\title{
Prevalence and correlates of gender inequitable norms among young, church-going women and men in Kinshasa, Democratic Republic of Congo
}

Hendrew Lusey ${ }^{1,2,3^{*}}$, Miguel San Sebastian ${ }^{2}$, Monica Christianson ${ }^{3}$ and Kerstin E. Edin ${ }^{3}$

\begin{abstract}
Background: Prolonged political instability may have exacerbated gender inequitable beliefs in the Democratic Republic of Congo (DRC). The aim of this study was to assess attitudes related to gender-equitable norms and its determinants among young, church-going women and men in Kinshasa, DRC.

Method: Data were collected through a cross-sectional survey with 291 church-going women and 289 men aged 18-24 years old, residing in three disadvantaged communes of Kinshasa. Variables included sociodemographic characteristics, attitudes towards gender equality, and responses to issues related to the gender-equitable men (GEM) scale. The GEM scale is a 24 item-questionnaire developed to measure attitudes towards gender equitable norms. Logistic regression was applied to discover the associations between the independent variables and the GEM outcome.

Results: Our study reflected the existence of attitudes hampering gender equality that were endorsed by both women and men. For example, $91.4 \%$ of women and $83 \%$ of men agreed with the statement "a woman's most important role is to take care of her home and cook for her family". Similarly, $88.3 \%$ of women and $82.9 \%$ of men concurred with the idea that men need more sex than women. These findings coexisted with a few equitable norms, because $93.7 \%$ of women and $92.3 \%$ of men agreed that a man and a woman should decide together if they want to have children. A positive association was found in both women and men between being educated, being single and separated and having supportive attitudes towards gender equality and a higher GEM scale score. Residency in Camp Luka and Masina was also a significant social determinant associated with equitable gender norms among men whilst job status was only significant among women.
\end{abstract}

Conclusion: While both women and men had high levels of gender inequitable norms, those with more education, single, and with supportive attitudes to gender equality had high GEM scale scores. The results highlight an urgent need for the church to challenge and change gender norms among church youths.

Keywords: Gender inequitable norms, Gender equity, Church youths, Masculinities, Cross-sectional survey, DR Congo

\footnotetext{
* Correspondence: Hendrewlusey@gmail.com

${ }^{1}$ World Council of Churches, Ecumenical HIV and AIDS Initiative and

Advocacy (EHAIA), Central Africa regional office, C/o Salvation Army

Headquarters, Avenue colonel Ebeya No. 23, B.P: 8636, Kinshasa Gombe,

Democratic Republic of Congo

${ }^{2}$ Epidemiology and Global Health, Department of Public Health and Clinical

Medicine, Umeå University, Umeå, Sweden

Full list of author information is available at the end of the article
}

(c) The Author(s). 2018 Open Access This article is distributed under the terms of the Creative Commons Attribution 4.0 International License (http://creativecommons.org/licenses/by/4.0/), which permits unrestricted use, distribution, and reproduction in any medium, provided you give appropriate credit to the original author(s) and the source, provide a link to the Creative Commons license, and indicate if changes were made. The Creative Commons Public Domain Dedication waiver (http://creativecommons.org/publicdomain/zero/1.0/) applies to the data made available in this article, unless otherwise stated. 


\section{Background}

The United Nations has prioritized the achievement of gender equality and women's empowerment as one of the main ways of ensuring the sustainable development goals [1]. The latest United Nations' Development Programme report stated that the gender equality index in sub-Saharan Africa (SSA) was low [2], potentially heightening unequal gender norms [3]. Both women and men receive societal messaging in early life and internalize unequal gender norms that dictate how women and men are supposed to behave [4]. For instance, women may have limited abilities to negotiate safer sex with male partners [5]. This attitude may be supported by a belief that considers women who carry condoms in their bags as 'promiscuous', pitting pregnancy and HIV prevention against social standards of women and sexuality [6-8].

Conversely, having unprotected sex with several partners and using violence against women might be common expectations for men, suggesting that men may drive HIV in sub-Saharan Africa [9, 10]. Despite a growing recognition that changing inequitable gender norms is key to successful HIV prevention, most studies are mainly focused on women, perceived as facing negative consequences to their health as a result of socio-economic and cultural disadvantages $[10,11]$. However, research reveals that gender equality is not possible without a meaningful men's engagement as partners in the processes and African countries that seriously seek to engage men in challenging social norms in relation to gender inequality tend to perform better in health [12]. For instance, a South African study examined how men responded to change towards gender equality and found that positive changes in gender beliefs and practices amongst men were correlated with improved health outcomes, such as increased condom use and HIV testing [10]. These results are consistent with studies arguing that gender transformative programmes can engage men as change agents [13].

Despite some ambivalence and resistance [9], research suggests that African men can learn to be positive about gender equality and actively support it in family and community life [14-16]. Research has also shown that integrating women and men as active partners in health interventions could be a useful strategy to transform gender inequalities $[16,17]$. In solidarity with women, men can be mobilized to endorse gender equality and this might be based on their respective desire for mutual respect and healthy lives [18]. Studies that examined gender equitable men (GEM) domains found evidence supporting that gender equitable attitudes can be a protective factor against sexually transmitted infections (STIs) and HIV. For instance, men with equitable attitudes were more likely to report healthy intimate relationships in which they discuss and use condom with partners [19], suggesting the importance to focus interventions already in young age to promote gender equity [20].

Churches are an integral part of social life in many African societies where they have wide networks and provide nearly $70 \%$ of health services and mainly to the most marginalized people [21]. Churches also promote moral norms among youths and may have unparalleled advantages over other sectors on addressing inequitable attitudes that may start in adolescence and may continue in adulthood in the absence of spaces for critically reflection on gender [22]. Specifically, churches may challenge and change norms of gender inequality informed by the church beliefs, teaching and practices in deprived urban areas where church leaders may continue to be seen as trusted figures among church youths [23].

For instance, a study conducted in Zambia showed the way some men exhibited harmful norms of masculinities of having sex with multiple partners, perpetrating violence against partners and drinking heavily [24]. When they were taught Christian norms of sexuality, 20\% of men in the study population adopted new patterns of behaviours in becoming faithful, sticking to their partners and stopping abusive alcohol consumption [24]. Research indicates that Bible studies may have opened up safe spaces where hegemonic norms of masculinities were discussed and challenged and alternative masculinities were suggested $[25,26]$. In spite of this, gender inequality remains deeply entrenched in many African churches where scriptures may be used to justify men as the dominant partners and women as subservient to the desire of men [24]. Hence engaging churches to address gender inequality may entail challenges, but with careful alignment as well as concerted actions, much can be gained.

While DRC is a country with vast natural resources, most Congolese live in abject poverty attributable to political instability, resource mismanagement, and armed conflict. DRC ranked both at the bottom of the Gender Equality Index (144th out of 148 countries) (Davis L, Fabbri P, Muthaka AI. Democratic Republic of Congo DRC: Gender Country Profile. Commissionned by the Swedish embassy in collaboration with DFID, the European Union Delegation and the Embassy of Canada in Kinshasa, Unpublished) and Human Development Index (176th out of 188) [27]. DRC did not achieve the Third Millennium Development Goal regarding gender equality (Rapport national Objectifs Millénnaires du Développement (OMD): Evaluation des progrès accomplis par la République Démocratique du Congo dans la réalisation des objectifs du millénaire en 2012, unpublished), making DRC one of the world's most challenging countries for women to live in [28]. The International Men and Gender Equality Survey (IMAGES) conducted a study in DRC in 2011, with participants 18-59 years old. It found that both Congolese women and men endorsed inequitable gender 
norms, viewing women as responsible for completing household chores and men as heads of the households [28].

The distribution of the population according to the religious affiliations in DRC is: Catholic (31\%); Protestant (30\%); other Christian Churches (34\%); indigenous religions (3\%); and Muslims (2\%) [29]. The Ecumenical HIV and AIDS Initiative and Advocacy (EHAIA) have sought to equip Congolese churches with support to promote equitable relationships but research on gender norms among church goers is lacking in DRC [30]. In an attempt to fill parts of this knowledge gap, our study aimed at assessing attitudes related to gender equitable norms and its determinants among young, church-going women and men in Kinshasa, DRC.

\section{Methods}

\section{Study design and setting}

This cross-sectional survey was carried out in Bumbu, Camp Luka, and Masina, three deprived peri-urban communes located in Kinshasa, the capital of DRC. The study sites were purposively selected given the youth work that the Église du Christ au Congo and Salvation Army was undertaking in these areas. In addition, the first author had collaborated with the leadership of these churches through his engagement with EHAIA [31].

\section{Recruitment and data collection}

The first author acquired the French translated questionnaire IMAGES from Promundo, a nongovernmental organisation founded in Brazil, which promotes equitable masculinities and equitable gender relations locally and globally [32]. We pretested the questionnaire among ten young women and ten young men from churches located in deprived communes of Kinshasa outside the study sites. The pre-test enabled the team of researchers to find out if the survey statements were culturally appropriate, understandable and clear for the local church youth context. Overall, the questionnaire was apposite to participants, except for a few items that the research team reworded to facilitate the respondents' understanding. For example, one item was initially labelled as follows: "work to achieve gender equality today benefit mostly well-to-do people". We changed the term "wellto-do-people" with "wealthy people".

The local parish pastors recruited eligible participants for this study based on the following criteria: to be young women and men (18-24 years old), belonging to the Salvation Army and the Église du Christ au Congo, living in the three selected communes during the time data was collected, able to read and write in French, and volunteered to be involved in the study. We decided to interview this target group because young people aged 18 years do not need parental permission for participating in research and those aged 24 years are still considered as youths according to the World Health Organisation definition [33].

The authorisation to carry out this study was provided by the leadership of both churches involved and the first author made contacts with the respective pastors who recruited the respondents at the congregational levels, mainly on Sundays. Once the church youths had gathered to take part in the study, the first author provided them with a self-administered questionnaire. The participants read and filled in the questionnaire autonomously within the relatively quiet church premises. In some instances, particularly for respondents who found certain statements difficult to grasp, the first author read the questions aloud to enable everyone to complete the survey. In general, it took approximately one hour for each participant to fill in the questionnaire.

The study was carried out from March to April, 2016 and in total 750 church-going youths were invited to participate. However, 88 participants were excluded for not meeting the inclusion criteria (being outside the appropriate age range, residing outside the study settings when data were collected, and belonging to a church other than the two selected churches): 67 did not turn up, and 15 declined the invitation for personal reasons. Finally, 580 were included, of whom 291 women and 289 men completed the questionnaires [31].

\section{Variables}

Our questionnaire is an adapted version of the International Men and Gender Equitable Survey (IMAGES) that was organised in three groups: sociodemographic characteristics, attitudes towards gender equality, and the Gender Equitable Men scale (GEM) [34]. In addition to the more general sociodemographic characteristics, our version of the questionnaire included a few specific items related to the targeted-church aspects of the study, such as the church membership and attendance.

\section{Sociodemographic characteristics}

Although gender was dichotomised into women and men [35], age was categorised into three groups (18-19, $20-21$, and 22-24 years old). The civil status included single, married/cohabiting, or separated. Education had three categories, primary, secondary, and university levels. We also collected some information regarding the respondents' residences and church affiliations. Although the variable main source of income included the head of their households (parents) or the respondents themselves, the labour status was categorised as currently employed, student, and unemployed. Each participant ticked only one option. 


\section{Attitudes towards gender equality}

This part of the original IMAGES questionnaire comprises several themes, notably men and women's practices, attitudes related to gender norms, gender equality, household dynamics and the men's involvement as fathers, intimate partner violence, health, and stress [28]. After we had piloted the original IMAGES questionnaire, we identified the most relevant items for the target group of young people. We shortened the GEM scale to assess items that were more specifically related to our study aim of assessing gender equality among young people. As an example, we did not include factors about parenting because most of our participants were unmarried youths. In both South Sudan and Uganda, they also adapted the IMAGES questionnaire by taking out certain statements considered as less appropriate for their studies [36, 37]. Our survey included 16 statements and responses fell into four categories as participants were asked to ascertain if they (1) completely or (2) partly agreed or they (3) partly or (4) completely disagreed with the statements. An index, created by the sum of all of the items, was developed and divided into terciles representing low, medium, and high levels of attitudes towards gender equality. Responses by young, church-going women and men to the questions regarding attitudes are reported in Appendix. Higher scores on the index denote greater gender equitable attitudes.

\section{The GEM scale}

The GEM scale was originally developed in low income settings in Brazil and used as a tool to measure changes in gender-related interventions [32, 38, 39]. The GEM scale has been used and validated in more than 20 countries around the world [40] including Brazil, India and Kenya [6], South Sudan [36], and in DRC [14, 28]. In the same vein, GEM has been used among women to examine gender norms in two earlier studies: in South Sudan [36] and DRC [28]. Initially, the GEM scale comprises 24 items related to gender and domestic chores, violence, sexual relationships, masculinities, and sexual and reproductive health. While our study included a list of 16 statements, we excluded the eight remaining GEM items after reflecting on the misunderstandings faced by young people involved in the pilot study [31]. A similar approach as ours, with regard to the GEM scale, was used in South Sudan and in DRC [28, 31, 36 . We summed up and grouped the items into terciles for descriptive purposes and later on, we dichotomised them using the mean as the cut-off point in low and high GEM scale for the regression analysis, representing low and high support for gender equitable norms [31, 41]. The Cronbach alpha regarding the GEM for women and men were 0.700 and 0.738 respectively, indicating an acceptable consistency of the scale [42].

\section{Data analysis}

As mentioned at the outset of this paper, the respondents' survey responses were written on the questionnaire format that the first author entered into an Excel sheet and transferred later on the whole data file to STATA 13.1 for statistical analysis. Because the study was looking for differences between women and men, all analyses were stratified by gender. First of all, the percentages of responses related to sociodemographic characteristics of young women and men, attitudes towards gender equality, and the GEM scale were calculated. Statistical gender differences for the various domains of the GEM scale were assessed using the chi-squared test. In the descriptive part, we used terciles as to do so is part of the GEM guidelines [32]. But we divided them into two groups according to the mean in order to do the logistic regression. In a second step, a logistic regression analysis was performed to find out associations between the sociodemographic characteristics and gender-equality attitudes of the participants with the GEM scale. Additionally, we calculated crude and adjusted odds ratios (OR) and their 95\% confidence intervals $(\mathrm{CI})$. Significant variables $(p<0.05)$ in the crude model were included in the adjusted models. Once the logistic regressions were established, the goodness-of-fit of the models was calculated using the Hosmer Lemeshow's goodness-of-fit test to estimate that the presumed models were appropriately specified in the third step. Finally, given the relative small sample, predictable variables were organized in five groups. $P$-values were not significant, indicating a good model fit.

\section{Ethical approval}

This study was approved in 2010 by the institutional review board of the School of Public Health at the University of Kinshasa, DRC. The study's aim and purpose were explained to the women and men taking part, who were ensured anonymity. Written informed consent was obtained from all study participants.

\section{Results}

Table 1 presents the sociodemographic characteristics of 580 participants, where $29.5 \%$ of women and $55.3 \%$ of men were $18-19$ years old. Nearly half $(49.4 \%)$ of the women and $65.4 \%$ of the men were single. About $16.8 \%$ of women and $9.3 \%$ of men surveyed had finished primary school. Similarly, $46.3 \%$ of women and $33.6 \%$ of men held a secondary school level. Finally, 37.7 and $29.8 \%$ of women and men surveyed, respectively, had a university degree. Most of the participants $(87.9 \%$ of women and $91.7 \%$ of men) belonged to the Salvation Army and the rest belonged to the Église du Christ au Congo. In the group of participants, $87.6 \%$ of women and $77.1 \%$ of men 
Table 1 Sociodemographic characteristics, attitudes towards gender equality, and Gender Equitable Men Scale Scores of young, church-going women and men in Kinshasa, Democratic Republic of Congo

\begin{tabular}{|c|c|c|}
\hline & $\begin{array}{l}\text { Young women } \\
N(\%)\end{array}$ & $\begin{array}{l}\text { Young men } \\
N(\%)\end{array}$ \\
\hline \multicolumn{3}{|l|}{ Age groups } \\
\hline $18-20$ & $86(29.5)$ & $160(55.3)$ \\
\hline $21-22$ & $69(23.7)$ & $67(23.1)$ \\
\hline $23-24$ & $136(46.7)$ & $62(21.4)$ \\
\hline \multicolumn{3}{|l|}{ Civil status } \\
\hline Married/cohabiting & $85(29.2)$ & $64(22.1)$ \\
\hline Single & $144(49.4)$ & $189(65.4)$ \\
\hline Separated & $62(21.3)$ & $36(12.4)$ \\
\hline \multicolumn{3}{|l|}{ Highest grade } \\
\hline Primary school & $46(16.8)$ & $27(9.3)$ \\
\hline Secondary school & $155(49.4)$ & $163(56.4)$ \\
\hline University & 89 (30.6) & $99(34.2)$ \\
\hline \multicolumn{3}{|l|}{ Place of residence } \\
\hline Bumbu & $46(15.9)$ & $105(36.4)$ \\
\hline Masina & $134(46.3)$ & 97 (33.6) \\
\hline Camp Luka & $109(37.7)$ & $86(29.8)$ \\
\hline \multicolumn{3}{|l|}{ Church belonging } \\
\hline Salvation Army & $256(87.9)$ & $265(91.7)$ \\
\hline Église du Christ au Congo & $35(12)$ & $24(8.3)$ \\
\hline \multicolumn{3}{|l|}{ Main source of income } \\
\hline Respondents themselves & $99(34)$ & $72(24.9)$ \\
\hline Heads of households & $192(65.9)$ & $217(75)$ \\
\hline \multicolumn{3}{|l|}{ Labour status } \\
\hline Unemployed & $103(35.4)$ & $133(46)$ \\
\hline Students & $100(34.3)$ & $91(31.4)$ \\
\hline Employed & $86(30.2)$ & $65(22.4)$ \\
\hline \multicolumn{3}{|l|}{ Attitudes to gender equality } \\
\hline Low & $50(17.1)$ & $58(20)$ \\
\hline Medium & 121 (41.5) & 179 (61.9) \\
\hline High & $120(41.2)$ & $52(17.9)$ \\
\hline \multicolumn{3}{|l|}{ GEM } \\
\hline Low & $162(55.6)$ & $112(38.7)$ \\
\hline Moderate & $122(41.9)$ & $87(30.1)$ \\
\hline High & $7(4.2)$ & $90(31.3)$ \\
\hline
\end{tabular}

reported that they attended the church services regularly. Most participants $(65.9 \%$ of women and $75 \%$ of men) reported the head of their household (their parents) as the main source of their income. Almost one-third (29.5\%) of women and close to one-fourth (22.4\%) of men stated that they were employed. Around one-fifth of both women (17.8\%) and men
(20\%) scored low in the gender equitable attitudes questionnaire, though a larger percentage of women scored higher than men (47.2\% versus $17.9 \%)$.

The next section summarises the views expressed by the participants by domains of the GEM scale (Table 2). More women (55.6\%) than men (38.7\%) had low scores on the GEM scale. Overall, the GEM domains related to gender and domestic chores, violence and sexual relationships were statistically significant among both women and men, whereas domains related to masculinities, sexual and reproductive health were not statistically significant. For example, $71.4 \%$ of women and $66 \%$ of men suggested that a woman's most important role is to care for her home and cook for her family. Additionally, approximately half of women and men agreed that, to be a man, a man needs to be tough. In the same vein, $83.4 \%$ of women and $82.7 \%$ of men concurred with the idea that they would be outraged if their partners asked them to use a condom. The views about the GEM domains related to violence and sexual relationships, however, differed more between women and men. For instance, $70.7 \%$ of women vs. $50.8 \%$ of men disagreed that a woman should tolerate violence in order to keep the family together. The majority of the women $(68.3 \%)$ and half $(50.8 \%)$ of the men agreed that men need more sex than women do.

The results of the logistic regression of factors associated with high GEM scale scores among young, church-going women and men is presented in Table 3. In the crude analysis, several factors such as being educated, being single and separated, place of residence and having supportive attitudes towards gender equality were significantly related to a higher GEM scale score for both women and men. However, job status and source of income were only significantly associated with a high GEM scale score among women. In the multivariate regression model, young, church-going men but not women who lived in Camp Luka and Masina had greater odds of having high GEM scores. For education, a higher GEM scale score was found among young, church-going women and men (although not significant for the latter) with secondary education and higher, compared with those having a primary level education. In addition, being a student as well as being unemployed were found to be positively associated with a high GEM scale score only among women. A strong association between attitudes to gender equality and the GEM scale score was found in both women and men. For instance, women with medium equity ( $\mathrm{AOR}=8.67 ; 95 \% \mathrm{CI}=3.60-20.89)$ and high equity ( $\mathrm{AOR}=4.00 ; 95 \% \mathrm{CI}=1.63-9.81)$ supported attitudes towards gender equality. This was similar for men with medium equity $(\mathrm{AOR}=2.56$; $95 \% \mathrm{CI}=1.30-5.04)$ and those with high equity (AOR $=7.09 ; 95 \% \mathrm{CI}=2.81-17.89$ ). 
Table 2 Scores of the Gender-Equitable Men Scale for young, church-going women and men

\begin{tabular}{|c|c|c|c|c|}
\hline & & Young women & Young men & P-value \\
\hline Survey statements & Responses & $N(\%)$ & $N(\%)$ & \\
\hline \multicolumn{5}{|l|}{ Gender and domestic chores } \\
\hline \multirow[t]{3}{*}{ A woman's most important role is to take care of her home and cook for her family } & Totally agree & $208(71.4)$ & $191(66)$ & \\
\hline & Partially agree & $58(19.9)$ & $49(16.9)$ & \\
\hline & Disagree & $25(8.5)$ & $49(16.9)$ & 0.01 \\
\hline \multirow[t]{3}{*}{ Changing diapers, giving a bath, and feeding kids is the mother's responsibility } & Totally agree & $186(63.9)$ & $185(64)$. & \\
\hline & Partially agree & $85(29.2)$ & $53(18.3)$ & \\
\hline & Disagree & $20(6.8)$ & $51(17.6)$ & $<0.05$ \\
\hline \multirow[t]{3}{*}{ A man should have the final word about decisions in his home } & Totally agree & $206(70.7)$ & $242(83.7)$ & \\
\hline & Partially agree & $58(19.9)$ & $29(10)$ & \\
\hline & Disagree & $27(9.2)$ & $18(6.2)$ & $<0.05$ \\
\hline \multicolumn{5}{|l|}{ Violence against women } \\
\hline \multirow[t]{3}{*}{ A woman should tolerate violence in order to keep the family together } & Totally agree & $48(16.4)$ & $109(37.5)$ & \\
\hline & Partially agree & $37(12.7)$ & $60(20.7)$ & \\
\hline & Disagree & $206(70.7)$ & $147(50.8)$ & $<0.05$ \\
\hline \multirow[t]{3}{*}{ There are times when a woman deserves to be beaten } & Totally agree & $79(27.1)$ & $147(50.8)$ & \\
\hline & Partially agree & $122(41.9)$ & $85(29.4)$ & \\
\hline & Disagree & $90(30.3)$ & $57(19.7)$ & $<0.05$ \\
\hline \multicolumn{5}{|l|}{ Sexual relationships } \\
\hline \multirow[t]{3}{*}{ Men need more sex than women do } & Totally agree & $199(68.3)$ & $147(50.8)$ & \\
\hline & Partially agree & $60(20.6)$ & $93(32.1)$ & \\
\hline & Disagree & $32(11)$ & 49 (19.8) & $<0.05$ \\
\hline \multirow[t]{3}{*}{ Men are always ready to have sex } & Totally agree & $175(60.1)$ & $131(45.3)$ & \\
\hline & Partially agree & $64(21.9)$ & $96(33.2)$ & \\
\hline & Disagree & $52(17.8)$ & $62(21.4)$ & $<0.05$ \\
\hline \multicolumn{5}{|l|}{ Masculinities } \\
\hline \multirow[t]{3}{*}{ To be a man, you need to be tough } & Totally agree & $154(52.9)$ & $145(50.1)$ & \\
\hline & Partially agree & $80(27.4)$ & $85(29.4)$ & \\
\hline & Disagree & $57(19.5)$ & $59(20.4)$ & 0.79 \\
\hline \multirow[t]{3}{*}{ If someone insults me, I will defend my reputation, with force if I have to } & Totally agree & $182(62.5)$ & $116(40.2)$ & \\
\hline & Partially agree & $47(16.1)$ & $91(31.6)$ & \\
\hline & Disagree & $62(21.3)$ & $82(28.1)$ & $<0.05$ \\
\hline \multirow[t]{3}{*}{ I would never have a gay friend } & Totally agree & $187(64.2)$ & $166(57.4)$ & \\
\hline & Partially agree & $34(11.6)$ & $53(18.3)$ & \\
\hline & Disagree & $70(24.6)$ & $70(24.2)$ & 0.06 \\
\hline \multicolumn{5}{|l|}{ Sexual and reproductive health } \\
\hline \multirow[t]{3}{*}{ I would be outraged if my partner asked me to use a condom } & Totally agree & $156(50.6)$ & $137(47.4)$ & \\
\hline & Partially disagree & $62(21.3)$ & $87(30.1)$ & \\
\hline & Disagree & $73(25)$ & $65(22.4)$ & $<0.05$ \\
\hline \multirow[t]{3}{*}{ A man and a woman should decide together if they want to have children } & Totally agree & $244(83.8)$ & $239(82.7)$ & \\
\hline & Partially agree & $26(8.9)$ & $28(9.6)$ & \\
\hline & Disagree & $21(7.2)$ & $22(7.6)$ & 0.93 \\
\hline \multirow[t]{2}{*}{ It is a woman's responsibility to avoid getting pregnant } & Totally agree & $128(43.9)$ & $119(49.1)$ & \\
\hline & Partially agree & $128(43.9)$ & $87(30.1)$ & \\
\hline
\end{tabular}


Table 2 Scores of the Gender-Equitable Men Scale for young, church-going women and men (Continued)

\begin{tabular}{|c|c|c|c|c|}
\hline & & Young women & Young men & P-value \\
\hline & Disagree & $35(12)$ & $83(28.7)$ & $<0.05$ \\
\hline \multirow[t]{3}{*}{ Men don't talk about sex, they just do it } & Totally agree & $170(58.4)$ & $119(41.1)$ & \\
\hline & Partially agree & $57(19.5)$ & $87(30.1)$ & \\
\hline & Disagree & $64(21.9)$ & $83(28.7)$ & $<0.05$ \\
\hline \multirow[t]{3}{*}{ Men should be embarrassed if they are unable to get an erection } & Totally agree & $119(40.8)$ & $153(52.9)$ & \\
\hline & Partially agree & $96(32.9)$ & $68(23.5)$ & \\
\hline & Disagree & $76(26.1)$ & $68(23.5)$ & $<0.05$ \\
\hline
\end{tabular}

Table 3 Factors related to a high Gender-Equitable Men Scale reported by young, church-going women and men: logistic regression analysis with crude and adjusted odds ratios (OR) and their 95\% confidence intervals (Cl)

\begin{tabular}{|c|c|c|c|c|}
\hline \multirow[b]{2}{*}{ Factors } & \multicolumn{2}{|l|}{ Women } & \multicolumn{2}{|l|}{ Men } \\
\hline & $\begin{array}{l}\text { Crude OR } \\
(95 \% \mathrm{Cl})\end{array}$ & Adjusted OR (95\% Cl) & $\begin{array}{l}\text { Crude OR } \\
(95 \% \mathrm{Cl})\end{array}$ & Adjusted OR (95\% Cl) \\
\hline \multicolumn{5}{|l|}{ Age } \\
\hline $23-24$ & 1 & - & 1 & - \\
\hline $21-22$ & $1.13(0.63-2.02)$ & - & $0.56(0.28-1.12)$ & - \\
\hline $18-20$ & $1.26(0.73-2.17)$ & - & $1.02(0.57-1.84)$ & - \\
\hline \multicolumn{5}{|l|}{ Education } \\
\hline Primary school & 1 & - & 1 & 1 \\
\hline Secondary school & $1.61(0.80-3.23)$ & $1.35(0.60-3.00)$ & $3.04(1.22-7.58)$ & $2.65(0.99-7.11)$ \\
\hline University & $2.21(1.05-4.65)$ & $3.14(1.28-7.67)$ & $3.43(1.33-8.84)$ & $2.54(0.90-7.16)$ \\
\hline \multicolumn{5}{|l|}{ Place of residence } \\
\hline Bumbu & 1 & 1 & 1 & 1 \\
\hline Camp Luka & $0.34(0.17-0.70)$ & $0.95(0.44-2.05)$ & $2.53(1.41-4.56)$ & $2.27(1.18-4.38)$ \\
\hline Masina & $0.79(0.40-1.55)$ & $0.53(0.23-1.21)$ & $3.10(1.75-5.52)$ & $3.29(1.73-6.25)$ \\
\hline \multicolumn{5}{|l|}{ Civil status } \\
\hline Married & 1 & 1 & 1 & 1 \\
\hline Single & $2.15(1.23-3.75)$ & $2.15(1.11-4.17)$ & $2.75(1.51-5.02)$ & $3.20(1.64-6.25)$ \\
\hline Separated & $1.21(0.61-2.40)$ & $1.93(0.83-4.50)$ & $2.75(1.18-6.39)$ & $3.54(1.36-9.21)$ \\
\hline \multicolumn{5}{|l|}{ Job status } \\
\hline Employed & 1 & 1 & 1 & - \\
\hline Students & $0.52(0.34-0.71)$ & $2.69(1.44-5.01)$ & $0.89(0.68-1.16)$ & - \\
\hline Unemployed & $2.69(1.44-5.01)$ & $1.57(1.05-2.34)$ & $1.05(0.78-1.40)$ & \\
\hline \multicolumn{5}{|l|}{ Church belonging } \\
\hline Salvation Army & 1 & - & 1 & - \\
\hline Église du Christ au Congo & $0.53(0.25-1.14)$ & - & $0.69(0.30-1.60)$ & - \\
\hline \multicolumn{5}{|l|}{ Main sources of income } \\
\hline Themselves & 1 & - & 1 & - \\
\hline Heads of household & $2.00(1.20-3.31)$ & $1.23(0.61-2.45)$ & $1.46(0.85-2.50)$ & - \\
\hline \multicolumn{5}{|l|}{ Attitudes to gender equality } \\
\hline Low equity & 1 & 1 & 1 & 1 \\
\hline Medium equity & $6.75(3.08-14.80)$ & $8.67(3.60-20.89)$ & $2.00(1.07-3.76)$ & $2.56(1.30-5.04)$ \\
\hline High equity & $2.23(1.01-4.90)$ & $4.00(1.63-9.81)$ & $9.33(3.84-22.63)$ & $7.09(2.81-17.89)$ \\
\hline
\end{tabular}




\section{Discussion}

Our study provides evidence of attitudes and beliefs that may hamper gender equality and demonstrates that women and men in this study endorsed inequitable gender norms. Nonetheless, a positive association was found for both women and men between being educated, being single and separated, and having supportive attitudes towards gender equality and higher GEM scale scores.

\section{GEM domains}

Overall, our findings revealed similarly poor gender-equity scores for both women and men for gender and domestic chores, masculinities, and sexual and reproductive health; these findings are in line with the DRC-IMAGES study [28]. For instance, our study indicated that most respondents considered men as heads of the household and women as caregivers. This may suggest a belief among men and women that women should accept subservient positions. Research has reported that some men and women in DRC tend to consider women as personal property whose job it is to carry out domestic chores after payment of the bride price [43]. Our findings about gender norms related to masculinity were also consistent with the DRC-IMAGES study, which stated that both Congolese women and men have internalised attitudes that support men's toughness [28]. Research revealed that these dominant forms of masculinities not only have a negative impact on girls and women but also undermine the health and well-being of boys and men [44]. Respondents largely reported agreement with statements of inequitable norms regarding sexual and reproductive health, which hold women as being primarily responsible for preventing pregnancy. However, these attitudes coexisted with a few positive gender-equitable norms. For example, almost all women and men (92.7 and 91.3\%, respectively) in our study, compared with 45.6 and $53.7 \%$ of women and men, respectively, in the DRC-IMAGES study, concurred with the idea that a man and a woman should decide together if they want to have children [28].

By contrast, respondents' views about violence against women and sexual relationships were sharply different among women and men. In this regard, the DRC-IMAGES study [28] and our study confirmed that more men $(79.2 \%)$ than women $(69 \%)$ agreed with the statement "there are times when a woman deserves to be beaten". It is worthwhile noting that not all of the results related to gender norms were inequitable. For instance, the statement "a woman should tolerate violence in order to keep the family together" met with disagreement from $70.7 \%$ of women and $50.8 \%$ of men in our study, compared with $45.1 \%$ of women and $34.3 \%$ of men in a recent Congolese study [43]. In the GEM-related domain of sexual relationships, $88.3 \%$ of women (our study) versus 89.6\% (DRC-IMAGES study) and $82.9 \%$ of men (our study) versus $70.5 \%$ (DRC-IMAGES study) affirmed that men need more sex than women [28].

Several issues might explain some of the differences between the DRC-IMAGES study [28] and ours. While the DRC-IMAGES study was carried out in North-Kivu in the eastern part of the country, which has faced and is still facing violent armed conflicts, our study was conducted in Kinshasa, the western part of DRC, which in comparison seems to be quite "peaceful" despite all its riots. The target group for the DRC-IMAGES study was people aged 1859 whereas in our study, we include the perspectives of church youths aged 18-24. Our study focuses on young church goers drawn from deprived urban areas compared to the general population particularly those who lived in rural areas outside Goma and in military bases near Goma as internal displaced people who were the target groups in the DRC-IMAGES study.

In comparison to the DRC-IMAGES study, our church-going youths mainly scored gender inequitable statements for several reasons. The prevailing notions of gender in DRC are largely based on norms rooted in unequal power relations characterized by violence experienced by women and men's domination in decision making process [28]. In addition, gender socialisation of both women and men may begin early in life in DRC and their behaviours may be rehearsed and carried out into adulthood particularly in deprived areas where youths may have limited opportunities for adhering to alternative masculinities and gender-equitable relationships [45].

We expected that our study population might have been different from the general public in terms of attitudes towards equality because of the church influence. Compared with DRC-IMAGES, our findings suggest that their attitudes were not so divergent. Support for gender inequitable norms by church youths might also be due to biased interpretations of some narrow Christian views about patriarchy, which tend to give more power to men, including the control of women's bodies and sexuality $[26,46]$. In certain churches, women are taught to keep silent about violence in relationships since the men deserve "respect" and anything that may lead men to lose that respect should not be exposed to others [47]. Therefore, understanding these gender perspectives may encourage the church to provide more targeted and focused teaching since gender equality is a fairly new topic in Congolese churches [30].

\section{Gender differences in GEM scale scores}

Our findings suggest that women endorsed most of the GEM inequitable statements, indicating that they may experience constant unequal power relationships and therefore internalized inequitable gender norms [28]. The DRC-IMAGES findings stated that women's responses to the GEM scale may be the result of their 
lived experiences rather than their true beliefs [28]. Because intimate-partner violence is highly prevalent in DRC [48], women's coping strategies may include the acceptance of inequitable practices and relationships as survival strategies rather than an option [49]. Our findings are also consistent with other studies examining the relationships of gender attitudes to women's autonomy [50], and to sexual and reproductive health [51].

A study conducted in Zambia suggested that women's attitudes and practices around gender norms might partly stem from interpretations of the biblical story of creation as evidence of women's inferiority in relation to men in relationships [45]. Also, both women and men might hold the view that women are not equal to men [52]. To this end, certain church teachings revolve around women serving men's sexual needs and subordinating their own sexual feelings to that of men even when they have little benefit. This may exclude women from their own decision making concerning sexual activities [53]. There is a need for the church to develop a sound theologically based-education that can address and challenge interpretations of biblical scriptures leading to gender inequality [54].

\section{Correlates of the GEM scale}

The level of education attained by women and men, especially those with a secondary education or higher, emerged as a consistent predictor of more equitable attitudes and is similar to that of the Mali-IMAGES study [3]. These two study findings suggest that educated people may have progressive views about gender equality and may be aware of its importance [55]. Therefore, educating young women and men about gender equality early in life can prove to be beneficial for increased gender equity when they enter into relationships [56]. If educated youth can internalise equitable gender norms and act on them in their daily lives, then a shift in generational gender norms can gradually take place in Africa.

We found that single women and men achieved high GEM scale scores, suggesting that those who may not have experienced a long term serious relationship might have not been exposed to unequal power relationships. And in turn, this might help explain why they have higher GEM scores. From this perspective, research has suggested that certain marriages might be seen as spaces surrounding harmful norms of masculinities, which may reinforce patriarchal attitudes that make it difficult to negotiate recent societal changes, such as gender equality $[57,58]$. Our study found a strong positive association between having supportive attitudes towards gender equality and a high GEM scale score in both women and men. This finding is consistent with a study that used the GEM scale to examine the effect on men's involvement in family planning and HIV services in Uganda [37]. The study findings suggested men's improvements in some health-seeking behaviours and practices, which included visiting health facilities, taking HIV tests, and using condoms; these behaviours were reported as positively affecting the health of both women and men [37]. The IMAGES findings showed that women who reported that their male partners exhibited more gender equitable behaviours were generally more satisfied with their relationship with their male partners [38].

\section{Methodological considerations}

Our study has some limitations that should be considered when interpreting the results. The relative small sample size could not have identified some relationships by using logistic regression, and a potential selection bias might have been operating because respondents were selected by parish pastors. Because the participants mainly came from the Salvation Army and from specific disadvantaged areas of Kinshasa, the findings might not be generalised to other urban or rural churches of the country. As with any survey carried out on sensitive issues regarding gender equity and sexuality and despite the promise of participant anonymity, some sensitive issues might have been under- and/or over-reported. Although the GEM scale was initially constructed for men, it was applied to both women and men participating in this study to make the findings comparable [59].

\section{Conclusion}

Although most research on gender equity attitudes focuses on men, our study findings suggest that both young women and men had high levels of gender inequitable norms. Hence, our study may have acted as a spotlight, revealing many harmful gender norms that may prevail in the churches and in the society at large. For instance, more women than men were likely to agree on these inequitable attitudes, which highlights how gender inequality is ingrained in both genders and hampers progress of equality. Therefore, churches need to work with both women and men to challenge expectations and harmful norms regarding femininities and masculinities. Overall, the reason why women supported most of the inequitable GEM statements requires further investigation. There is an opening for churches to join hands and use their positions as social institutions that establish and enforce social norms to respond to this challenge.

Women and men with more education, single, and with supportive attitudes for more gender equality had high GEM scale scores. The association between higher educational levels and equitable norms seems to reinforce the importance of education. The church can encourage education, assist youths who have to leave school for 
income-generating activities, and provide different educational opportunities, especially those that integrate promotion of gender equity. The churches also need to reach young women and men with messages and role models that promote healthy, non-violent and gender equitable lifestyles among church youths.

\section{Implications for practice}

Our study findings indicate the importance of the churches in developing policies and programmes that address gender inequality with particular focus on young people.

1. Churches need to acknowledge the critical responsibilities that women and men can have as key partners in strengthening the response to gender equality and ensure that church staffs, policies and programmes seek to facilitate and advocate for their meaningful involvement.

2. Churches should create, support, and reinforce gender equitable norms, as well as foster alliances with other stakeholders working towards a more gender-equitable future.

3. The focus of church-youth interventions can be broadened to achieve gender-equitable attitudes and practices not just at the individual and family levels but to exercise a wider influence also on community and institutional levels across DRC.

\section{Abbreviations}

AOR: Adjusted odds ratio; Cl: Confidence intervals; DRC: Democratic Republic of Congo; EHAIA: Ecumenical HIV and AIDS Initiative and Advocacy; GEM: Gender-equitable men; HIV: Human Immunodeficiency Virus; IMAGES: International Men and Gender Equality Survey; OR: Odds ratios; STI: Sexually Transmitted Infections; UN: United Nations; Vs: Versus

\section{Acknowledgements \\ The authors wish to thank the Salvation Army and the Église du Christ au Congo leaderships for authorising this study to be carried out in their respective church premises. We appreciate the generosity of research participants in sharing their perspectives regarding gender equity.}

\section{Funding}

This research was partially funded by the Umeå Centre for Global Health Research, funded by FAS, the Swedish Council for Working Life and Social Research, Grant number 2006-1512 and the Swedish Center Party Donation for Global Research Collaboration.

Availability of data and materials

All data underlying this study is included in the article.

\section{Authors' contributions}

This is a jointly researched and written paper. HL contributed to the conception of the study, designed the study, managed the data collection, performed the analysis, interpreted the data and wrote the first draft of this manuscript. MS contributed to the study design and supported HL in data analysis, interpretation and supervised the write up of the manuscript. MC and KEE contributed to the conception of the study and read critically this manuscript. All the authors participated in the critical discussion of the results, read and approved the final manuscript.

\section{Ethical approval and consent to participate}

This study was approved in 2010 by the institutional review board of the School of Public Health at the University of Kinshasa, DRC. The study's aim and purpose were explained to the women and men taking part, who were ensured anonymity. Written informed consent was obtained from all study participants.

\section{Appendix}

Table 4 Attitudes towards gender equality related to relationships between men and women among church-going young women and men in Kinshasa, DRC

\begin{tabular}{|c|c|c|c|c|c|c|c|c|}
\hline \multirow[t]{3}{*}{ Statements } & \multicolumn{2}{|c|}{ Completely agree } & \multicolumn{2}{|c|}{ Partly agree } & \multicolumn{2}{|c|}{ Partly disagree } & \multicolumn{2}{|l|}{ Disagree } \\
\hline & Women & Men & Women & Men & Women & Men & Women & Men \\
\hline & $N(\%)$ & $N(\%)$ & $N(\%)$ & $N(\%)$ & $N(\%)$ & $N(\%)$ & $N(\%)$ & $N(\%)$ \\
\hline $\begin{array}{l}\text { When women work they are taking jobs away from } \\
\text { men }\end{array}$ & $66(22.68)$ & 109 (37.72) & $49(19.92)$ & $57(19.72)$ & $29(11.79)$ & $25(8.65)$ & $102(41.46)$ & $61(21.11)$ \\
\hline $\begin{array}{l}\text { When women get rights, they are taking rights way } \\
\text { from men }\end{array}$ & $53(21.29)$ & $91(31.49)$ & $43(17.27)$ & $71(24.57)$ & $37(14.86)$ & $42(14.53)$ & $116(46.59)$ & $55(19.03)$ \\
\hline Rights for women mean that men lose out & $26(10.97)$ & $51(17.65)$ & $29(12.24)$ & $41(14.19)$ & $34(14.35)$ & $44(15.22)$ & $148(62.45)$ & $101(34.95)$ \\
\hline $\begin{array}{l}\text { When a woman is raped, she usually did something } \\
\text { careless that put herself in that situation }\end{array}$ & $75(27.47)$ & $91(31.49)$ & $34(12.45)$ & $71(24.75)$ & $43(15.75)$ & $52(17.99)$ & $121(44.32)$ & $47(16.26)$ \\
\hline In some cases, women usually want it to happen & $34(14.05)$ & $67(23.18)$ & $27(11.16)$ & $80(27.68)$ & $25(10.33)$ & $38(13.15)$ & $156(64.46)$ & $73(25.36)$ \\
\hline $\begin{array}{l}\text { If a woman did not fight back, you can't really say it } \\
\text { was rape }\end{array}$ & $61(23.74)$ & $117(40.48)$ & $57(22.18)$ & $77(26.47)$ & $45(17.51)$ & $31(10.73)$ & $94(36.58)$ & $46(15.92)$ \\
\hline $\begin{array}{l}\text { In any case, one would have to question whether } \\
\text { the "victim" is promiscuous }\end{array}$ & $100(37.59)$ & $122(42.26)$ & $40(15.04)$ & $51(17.65)$ & $29(10.90)$ & 39 (13.49) & $97(36.58)$ & $57(15.92)$ \\
\hline $\begin{array}{l}\text { In any case, one would have to question whether } \\
\text { the "victim" has a bad reputation }\end{array}$ & $83(29.75)$ & $88(30.45)$ & $47(16.85)$ & $78(26.99)$ & $34(12.19)$ & $44(15.22)$ & $115(41.22)$ & $58(20.87)$ \\
\hline
\end{tabular}




\section{Consent for publication}

Not applicable.

\section{Competing interests}

The authors declare that they have no competing interests.

\section{Publisher's Note}

Springer Nature remains neutral with regard to jurisdictional claims in published maps and institutional affiliations.

\section{Author details \\ ${ }^{1}$ World Council of Churches, Ecumenical HIV and AIDS Initiative and Advocacy (EHAIA), Central Africa regional office, C/o Salvation Army Headquarters, Avenue colonel Ebeya No. 23, B.P: 8636, Kinshasa Gombe, Democratic Republic of Congo. ${ }^{2}$ Epidemiology and Global Health, Department of Public Health and Clinical Medicine, Umeå University, Umeå Sweden. ${ }^{3}$ Sexual and Reproductive Health, Department of Nursing, Umeå University, Umeå, Sweden.}

\section{Received: 16 November 2017 Accepted: 22 June 2018} Published online: 17 July 2018

\section{References}

1. United Nations. "Sustainable development goals" Accessed 10th Sept 2017. http://www.un.org/sustainabledevelopment/sustainable-development-goals/ \#. 2016

2. United Nations Development Programme. Human Development Report 2016. Human Development For Every one. Copyright @ 2016. New York: United Nations Development Programme; 2016.

3. Slegh H, Barker G, Toliver M, Bah A, Keita M. Men, gender equality and gender relations in Mali. In: Findings from the international men and gender equality survey; 2013.

4. Pulerwitz J, Barker G, Segundo M, Nascimento M, et al. Promoting more gender equitable norms and behaviours among young men as an HIV/AIDS prevention strategy. In: Horizon Final Report. Washington, DC: Population Council; 2006.

5. Bayeh $\mathrm{E}$. The role of empowering women and achieving gender equality to the sustainable development in Ethiopia. Soc Sci Med. 2016;2(1):37-42.

6. Pulerwitz J, Michaelis A, Verma R, Weiss E. Addressing gender dynamics and engaging men in HIV programs: lessons learned from horizons research. Public Health Rep. 2010;125(2):282-92.

7. Childhope. New York. In: Gender, sexuality and attitudes related to AIDS among low-income youth and street youth in Rio de Janeiro, Childhope. Brazil; 1997

8. Barker G, Ricardo C, Nascimento M, Olukoya A, Santos C. Questioning gender norms with men to improve health outcomes: evidence of impact. Global Public Health. 2010;5(5):539-53.

9. Shefer T, Kruger LM, Schepers Y. Masculinity, sexuality and vulnerability in "working" with young men in south African contexts: "you feel like a fool and idiot... a loser". Culture, Health \& Sexuality. 2015;17(S2):S96-S111.

10. Dworkin SL. Men at risk: masculinity, heterosexuality and HIV prevention, new York University press. In: New York and London; 2015.

11. Muwonwa M. "Dying to be women": exploration and implications of narrative parameters of female youth sexuality in Zimbabwe. African Journal of AIDS Research. 2017;16(3):185-91

12. Doyle K, Levtov R, Barker G, et al. Gender transformative Bandebereho couples' interventions to promote male engagement in reproductive and maternal health and violence in Rwanda. Findings from a randomised trials. Plus one. 2018;13(4):1-16.

13. Van der Berg W, Godana P, Hendricks L, Hatcher A, Dworkin SL. Shifts in fatherhood beliefs and parenting practices following a gendertransformative health programme in eastern cape, South Africa. Gend Dev. 2013:21:111-25

14. Levtov R, Barker G, Contreras-Urbina B, Heilman B, Verma R. Pathways to gender equitable men: findings from the international men and gender equality survey in eight countries. Men Masculinities. 2014;17(5):467-501.

15. Peacock D \& Barker G. Working with men and boys to promote gender equality: a review of the field and emerging approaches. Expert meeting. Prevention of violence against women and girls. . Bangkok UN women, 2012.
16. Colvin C, Peacock D, Human O. Report on formative research conducted for Sonke gender justice Network's "one man can campaign". Cape town: Sonke gender justice Network; 2009.

17. Barker G, Peacock D. Making gender truly relational: engaging men in transforming gender inequalities, reduce violence and preventing HIV: A publication of the AIDS legal Network; 2010.

18. Jewkes R, Morrell R, Hearn J, Lundqvist E, Blackbeard D, Lindegger G, Quayle M, Sikweyiya Y, Gottzen L. Hegemonic masculinity: combining theory and practice in gender interventions. Culture, Health, Sexuality. 2015;17(S2):S12-7.

19. Middlestadt S, et al. Gender norms as a key factor that influences sexual and reproductive health behaviours among Ethiopian men, and implication for behavior change programs. Washington: Academy for educational Development; 2007.

20. Pulerwitz J, Hughes L, Mehta M, Kidanu A, Verani F, Tewolde S. Changing gender norms and reducing intimate partner violence: results from a quasiexperimental intervention study with young men in Ethiopia. Am J Public Health. 2014;13(2014):e1-6.

21. Haddad B, Olivier J. The potentials and perils of partnership: Christian religious entities and collaborative stakeholders responding to HIV and AIDS in Kenya, Malawi and DR Congo. Study commissioned by Tearfund and UNAIDS. Interim report. In: African health assets Programmes; 2008.

22. Nweneka C. Sexual practices of church youths in the era of HIV/AIDS: playing the ostrich. AIDS Care. 2007;19(8):966-9.

23. Chitando E. Challenging masculinities: religious studies, men and HIV in Africa. J Construct Theology. 2008;11(4):55-69.

24. Van Klinken AS, Chitando E. Masculinities HIV. Religion in Africa. In: Tomalin E, editor. The Routledge handbook of religions and global development. New York: Routledge; 2015. p. 127-37.

25. Loots L. Transforming masculinities: Great Lake region summary report: social attitudes and practices of men in relation gender. London: Tearfund; 2014.

26. Van Klinken AS. Men in the remaking: conversion narratives and born-again masculinity in Zambia. J Relig Afr. 2012;42(3):215-39.

27. UNDP. Human Development Reports. Work for Human Development. United Nations Development Programmes. New York: One United Nations Plaza. 2015.

28. Slegh H, Barker G, Levtov R. Gender relations, sexual and gender basedviolence and the effects of conflict on women and men in North Kivu, Eastern Democratic Republic of Congo: results from the International Men and Gender Equality Survey (IMAGES). Washington, DRC, and Capetown, South Africa, Promundo-US and Sonke Justice; 2014.

29. Macro International. Demographic and Health Survey. DR Congo. République Démocratique du Congo: Enquête démographique et de santé. Rapport préliminaire, Maryland, MD: Ministère du Plan et Ministère de la santé; 2007.

30. Lusey H, San Sebastian M, Christianson M, Dahlgren L, Edin K. Conflicting discourses of church youths on masculinity and sexuality in the context of HIV in Kinshasa, Democratic Republic of Congo. Sahara. J of Soc Aspects of HIV\&AIDS. 2014;11(1):83-94.

31. Lusey H, San Sebastian M, Christianson M, Edin K. Factors associated with gender equality among church-going young men in Kinshasa, Democratic Republic of Congo: a cross-sectional study. Int J Equity Health. 2017;16:213

32. Pulerwitz J, Barker J. Measuring attitudes towards gender norms among young men in Brazil. Men Masculinities. 2008;10(8):322-38.

33. World Health Organisation. Global accelerated action for the health of adolescents (AA-HA!): Guidance to support country implementation, Geneva. 2017

34. The International Men and Gender Equality survey (IMAGES). Men and Gender Equality Policy Project, "IMAGES Survey questionnaires". http://www. icrw.org/pdf_download/133/11d0b3f6637ab098b65f976a8653c7db Accessed 10 Sept 2017.

35. Krieger N. Gender, sexes, and health: what are the connections - and why does it matter? Int J Epidemiol. 2003:32:652-7.

36. Scott J, Averbach S, Modest AM, Cornish S, Spencer D, Murphy M, Parmar P. Influences of sex, age, and education on attitudes towards gender inequitable norms and practices in South Sudan. Global Public Health 2013;9(7):773-86.

37. Ghanotakisa E, Hokeb T, Wilcherb R, Mercerb S, Bobrowa EA, Namubiruc M, Katirayia L, Mandera I. Evaluation of a male engagement intervention to transform gender norms and improve family planning and HIV service uptake in Kabale, Uganda. Global Public Health. 2016; https://doi.org/10. 1080/17441692.2016.1168863. 
38. Barker G. Evolving men: initial results from the International Men and Gender Equality Survey (IMAGES), Washington, D.C. International Center for Research on Women (IRCW) and Institute Promundo. 2011.

39. Nanda G. Compendium of Gender Scales. FHI 360/C-Change. Accessed on 13 Mar 2017 http://www.c-hubonline.org/sites/default/files/resources/main/ C-Change_Gender_Scales_Compendium.pdf. 2011.

40. Singh A, Verma A, \& Barker G. Measuring gender attitudes: using gender equitable men scale (GEMS) in various socio-cultural settings. In making women count: an annual publications on gender and evaluation by UN Women Multi Country Office for India, Bhutan, Sri Lanka and Maldives (pages 61-98). Chanakyapuri, New Delhi, India: UN Women.

41. Nanda G, Schuler SR, Lenzi R. The influence of gender attitudes on contraceptive use in Tanzania: new evidence using husbands' and wives' survey data. J Biosoc Sci. 2013;45:331-44.

42. Streiner DL, Norman GR. Health measurement scales: a practical guide to their development and use. New York: Oxford University Press; 2003.

43. Sandilands M, Jewkes R, Baghuna Lele U, Scott N. Does faith matter? Faith engagement, gender norms and violence against women and girls in conflict-affected communities: Baseline research in Ituri Province, Democratic Republic of Congo. UK:: Tearfund; 2017.

44. Peacock D, Barker G. Working with men and boys to prevent gender-based violence: principles, lessons learnt, and ways forward. Men and masculinities. 2014;17(5):578-99.

45. Kayembe KP, Mapatano MA, Busangu FA, et al. Correlates of ever had sex of recent sex among teenagers and young unmarried adults in the Democratic Republic of Congo. AIDS Behav. 2008;12:585-93.

46. Moyo F. Sex, gender and HIV/AIDS in Malawi. Threats and challenges to women being church. J Constr Theol. 2005;10(1):85-102.

47. Phiri IA. Why does God allow our husbands to hurt us?: overcoming violence against women. J Theol South Afr. 2002;114:25.

48. Amber P, Palermo T, BrendenKamp C. Estimates and determinants of sexual violence against women in the Democratic Republic of Congo. Am J Public Health. 2011;101(6):1060-7.

49. Hilker LM, Jacobson J, Modi A. The realities of adolescent girls and young women in Kinshasa: research about girls, by girls. UKAID. 2016;

50. Jejeebhoy SJ. Convergence and divergence in spouses' perspectives on women's autonomy in rural India. Stud Fam Plan. 2002:33:299-308.

51. Stephen R, Bartel D, Rubardt M. Construct of power and equity and their association with contraceptive use among men and women in rural Ethiopia and Kenya. Global Public Health. 2012;7(6):618-34.

52. Maskens M. The Pentecostal reworking of male identities in Brussels: producing moral masculinities. Etnofrica. 2015;19(2):23-45.

53. Van Klinken AS. Male Headship as Male Agency: An Alternative Understanding of a "Patrichal" African Pentecostal Discourse on Masculinity. Relig and Gend. 2011;1(1):104-24.

54. West G. "The contribution of Tamar's story to the constructive of alternative African masculinities", redemptive masculinities: men, HIV and religion. Chitando, E \& Shirongoma, S (eds) Geneva, World Council of Churches Publications, 173-192. 2012.

55. Greene M, Omar R, Pawlak P. Masculinities, social change, and development. World development report 2012. Gender equality and development. Background paper. 2011:

56. Gibbs A, Willan S, Misselhorn A, Mangoma J. Combined structural interventions for gender equality and livelihood security: a critical review of the evidence from southern and eastern Africa and the implications for young people. J Int AIDS Soc. 2013;15(Supl 1):1-10.

57. Sideris T. "You have to change and you don't know how": contesting what it means to be a man in rural South Africa. Afr Stud. 2004;63:29-49.

58. Dworkin SL, Hatcher AM, Colvin C, Peacock D. Impact of a gender transformative HIV and antiviolence programmes on gender ideologies and masculinities in two rural. South African communities Men and Masculinities. 2013;16(2):1-17.

59. Pulerwitz J, Michaelis A, Weiss E. Looking back, moving forward: promoting gender equity to fight HIV. Horizons studies 1999-2007. In: Horizons Synthesis Background Papers. Washington, DC: Population Council; 2010.

\section{Ready to submit your research? Choose BMC and benefit from:}

- fast, convenient online submission

- thorough peer review by experienced researchers in your field

- rapid publication on acceptance

- support for research data, including large and complex data types

- gold Open Access which fosters wider collaboration and increased citations

- maximum visibility for your research: over $100 \mathrm{M}$ website views per year

At BMC, research is always in progress.

Learn more biomedcentral.com/submissions 